\title{
Physiotherapy interventions for pain management in haemophilia: A systematic review
}

\section{Paul McLaughlin $^{1,2}$ (D) | Michael Hurley ${ }^{1}$ | Pratima Chowdary ${ }^{2}$ (D) | Kate Khair ${ }^{3}$ (D) | David Stephensen ${ }^{4}$}

${ }^{1}$ St George's University of London and Kingston University, London, UK

${ }^{2}$ Katharine Dormandy Haemophilia and Thrombosis Centre, Royal Free Hospital, London, UK

${ }^{3}$ Centre for Outcomes and Experience Research in Child Health, Illness and Disability (ORCHID) Research Unit, Great Ormond Street Hospital for Children NHS Trust, London, UK

${ }^{4}$ East Kent Hospitals University NHS Foundation Trust, Kent, UK

\section{Correspondence}

Paul McLaughlin, Haemophilia Centre and Thrombosis Unit, Royal Free London NHS Foundation Trust, Pond St, London NW3 2QG, UK.

Email: p.mclaughlin@nhs.net

Funding information

Paul McLaughlin is funded by a National Institute of Health Research (NIHR) Clinical Doctoral Research Fellowship (Ref: ICACDRF-2017-03-050) for this research project.

\begin{abstract}
Purpose: Approximately 35\%-50\% of people with haemophilia (PWH) report living with chronic musculoskeletal pain. Although exercise based rehabilitation is effective for pain in other arthritises, there are no published guidelines for management of chronic pain in PWH. This review aims to evaluate and appraise the current evidence of effectiveness of physiotherapy interventions on (a) pain intensity, (b) quality of life (QoL) and (c) function in PWH.

Methods: A systematic review of five databases AMED and CINAHL, EMBASE and MEDLINE and PEDro, as well as trial registries, grey literature and hand searching key journals was completed. Included studies were critically appraised and evaluated for risk of bias. The GRADE approach was used to rate the quality of the evidence.

Results: Nine trials consisting of 235 participants met the inclusion criteria. All studies had an overall risk of bias with low methodological quality. Meta-analysis was not possible due to heterogeneity across trials. Studies comparing a range of physiotherapy interventions against no intervention showed no clear beneficial effect on pain intensity or QoL. Only one study, investigating hydrotherapy or land-based exercise against control, showed positive effect for pain intensity, but rated very low on GRADE assessment. Studies comparing one physiotherapy intervention against another showed no clear benefit on pain intensity, QoL or function. LASER with exercise and hydrotherapy were shown to have some positive effects on pain intensity, but no clear benefit on function.

Conclusions: At present, there is limited evidence for the use of physiotherapy interventions in addressing the issue of pain in PWH. Better designed trials with higher quality and explicit methodology along with user involvement are needed to assess the efficacy of any proposed intervention.
\end{abstract}

\section{KEYWORDS}

arthropathy, Haemophilia, pain management, physiotherapy 


\section{1 | INTRODUCTION}

Haemophilia is an inherited bleeding disorder characterized by recurrent and spontaneous bleeding into joints and muscles and fatal bleeding in the untreated state., ${ }^{1,2}$ People with haemophilia (PWH) experience transient episodes of acute pain from an early age from musculoskeletal bleeding episodes. Despite replacement therapy, some PWH continue to have bleeding into their joints and muscles, which can lead to debilitating arthritis with chronic and recurrent pain. ${ }^{3}$

People with haemophilia over the age of 65 had no access to regular treatment until they were in adulthood, with those currently aged in their 40's having no access to effective treatment for the majority of their childhood. ${ }^{4}$ Consequently, many PWH have chronically painful, multi-joint haemophilic arthritis, involving elbow, knee and ankle joints. ${ }^{5-7}$

Between $35 \%$ and $50 \%$ of $\mathrm{PWH}$ report living with chronic musculoskeletal pain, ${ }^{7-10}$ with $40 \%$ reporting their pain is poorly managed by their healthcare provider. ${ }^{8} \mathrm{PWH}$ living with pain report limitations in mobility and independence, increased anxiety, poor quality of life and frustration due to restrictions in activities of daily living.,11,12

A recent systematic review of management of multisite osteoarthritis (OA) found that exercise interventions may have moderate benefits on pain, function and quality of life. ${ }^{13}$ More specifically, aerobic exercise has been shown to be effective for pain management and functional improvements in rheumatoid arthritis ${ }^{14}$ and in OA when used with mind-body interventions. ${ }^{15}$ However, although pain is a widespread problem in haemophilia, there are no published guidelines for the physiotherapy of management of chronic arthritic joint pain in this population.

\section{1 | Objective}

This review aims to evaluate and appraise the current evidence of the effects of physiotherapy interventions on (a) pain intensity, (b) quality of life and (c) function in $\mathrm{PWH}$.

\section{2 | METHODS}

\section{1 | Protocol and registration}

The protocol was registered with the International Prospective Register of Systematic reviews (PROSPERO number: CRD42018116482). Reporting is in accordance with the Preferred Reporting Items for Systematic Reviews and Meta-Analyses (PRISMA) statement. ${ }^{16}$

\section{2 | Eligibility criteria}

Study design for inclusion was those described as randomized controlled trials and quasi-experimental studies including controlled studies, before and after and interrupted time studies, comparing to no intervention/routine care group or between group comparison of one treatment intervention against another.

Studies describing any physiotherapy/rehabilitation/physical therapy intervention that had pain intensity, functional outcomes and health related quality of life as outcome measures were included.

Studies with participants of any age with a diagnosis of mild, moderate or severe haemophilia (A or B), and/or haemophilic arthritis were included. Those with participants with a diagnosis of an inhibitor (antibody to factor VIII or IX) and co-morbidities were not excluded. There was no restriction in country or care settings for studies.

Studies that investigated joint disease or pain as a result other inherited bleeding disorders such as von Willebrand disease were excluded.

\section{3 | Information sources}

A systematic search of the literature was conducted from the date of database conception to 20/07/2018, with a follow-up search again on 07/09/2018 (PML). The approaches used were as follows:

1. AMED (EBSCO), CINAHL (EBSCO), EMBASE (OVID), MEDLINE (OVID) and PEDro

2. Cochrane central register of controlled trials

3. Trial registries-clinicaltrial.gov, international trials registry, EU clinical trials register

4. Grey literature

5. Hand searching key journals

6. Checking reference lists of previous related systematic reviews in haemophilia

7. Hand searched abstract book of EAHAD congress (European Association of Haemophilia and Associated Disorders) 20002018 and WFH (World Federation of Haemophilia) world congresses 2000-2018

Only studies published in the English language were included.

\section{4 | Search strategy}

Figure 1 details the search strategy used across each database. Iterative refinement of the search strategy was achieved after multiple practice searches using potential search terms and associated subject headings. The university version of OVID and EBSCO search platforms maps to subject headings by default. The search strategy was discussed in detail and endorsed by the University librarian (AE-J).

\subsection{Study selection}

One reviewer (PML) independently carried out the search strategy on the listed databases. Results were saved, duplicates removed and 
FIGURE 1 Search strategy of terms for all databases [Colour figure can be viewed at wileyonlinelibrary.com]

\begin{tabular}{|c|c|c|}
\hline Database/register & Search years & Search terms \\
\hline AMED (EBSCO) & 1985-present & $\#$ \#(a)emophilia AND physio*/ physical*-therapy \\
\hline CINAHL (EBSCO) & 1961-present & $\#$ \#(a)emophilia AND physio*/ physical*-therapy \\
\hline EMBASE (OVID) & 1976- present & $\begin{array}{l}\# 1 \exp \mathrm{h}^{*} \text { emophilia } \\
\# 2 \text { exp pain }\end{array}$ \\
\hline MEDLINE (OVID) & 1964-present & $\begin{array}{l}\text { \#3 } 1 \text { AND } 2 \\
\text { \#4 exp physio*/physical"-therapy } \\
\text { \#5 exp manual therapy or exp manipulative medicine } \\
\text { \#6 exp hydrotherapy or exp "aquatic exercise" } \\
\text { \# exp electrotherapy or exp "electrophysical agents" } \\
\text { \#8 exp rehabilitation or "home rehabilitation" or } \\
\text { "rehabilitation medicine" or "exercise supervised" or } \\
\text { "exercise unsupervised" } \\
\text { \# exp "patient education" } \\
\text { \#10 } 4 \text { or } 5 \text { or } 6 \text { or } 7 \text { or } 8 \text { or } 9 \\
\# 113 \text { AND } 10 \\
\# 12 \text { "randomi*ed controlled trial" or "controlled trial" or } \\
\text { randomi*ed } \\
\# 1311 \text { AND } 12 \text { (filter limits Full Text and English Language) }\end{array}$ \\
\hline PEDro & & $\#$ H(a)emophilia \\
\hline www.clinicaltrials.gov & & $\#$ \#(a)emophilia AND physio*/ physical*-therapy \\
\hline $\begin{array}{l}\text { International Trials registry } \\
\text { http://apps.who.int/trialsearch/ }\end{array}$ & & $\#$ H(a)emophilia AND physio*/ physical*-therapy \\
\hline $\begin{array}{l}\text { EU Clinical Trials Register } \\
\text { www.clinicaltrialsregister.eu }\end{array}$ & & $\# \mathrm{H}(\mathrm{a})$ emophilia AND physio*/ physical*-therapy \\
\hline
\end{tabular}

then imported to the Rayyan platform, ${ }^{17}$ enabling two reviewers (PML, DS) to independently review titles and abstracts whilst blinded from each other. Once each reviewer had completed their check, the abstracts were unblinded. We compared those which had been accepted, rejected and were undecided by both reviewers, and discrepancies between reviewers $(n=2)$ were discussed and a consensus reached.

Full texts of agreed abstracts were retrieved and evaluated independently (PML, DS) to determine eligibility for inclusion in the systematic review.

\section{6 | Data collection process}

A data extraction proforma was developed using the Cochrane Airways group template (https://airways.cochrane.org/data-colle ction). One reviewer (PML) extracted data studies, and a second reviewer (DS) checked extracted data for accuracy. One author was contacted for further information, and data were received. ${ }^{18}$

\section{7 | Data items}

Information extracted from each trial included study design, participant information, interventions, comparison interventions, outcome measures (pre- and postintervention, follow-up if available), results including pain, function and quality of life.

\subsection{Risk of bias in individual studies}

The Cochrane Risk of Bias assessment tool was used to assess included papers and was carried out independently by two authors (PML, DS). Criteria of unclear, low or high risk of bias were assigned against selection bias, performance bias, detection bias, attrition bias, reporting bias and any other identified bias.

\section{9 | Methods of analysis}

Cochrane collaboration software (RevMan version 5.3$)^{19}$ was used to collate and analyse study data.

Mean change from baseline to follow-up and standard deviation of mean difference (MD) was calculated for input into RevMan. Using a fixed effects model, mean differences $\pm 95 \%$ confidence interval (Cl) per intervention were calculated. Studies were grouped into (a) physiotherapy intervention vs no intervention and (b) physiotherapy intervention A vs physiotherapy intervention B.

A narrative synthesis of the evidence was completed including the use of the GRADE approach in grading evidence quality. ${ }^{20}$ The GRADE system uses eight criteria against which to assess the quality of evidence as either high, moderate, low or very low. They are (a) risk of bias, (b) inconsistency, (c) indirectness, (d) imprecision, (e) publication and ( $f$ ) other (i. large effect, ii. dose response, iii. no plausible confounding-only these assessments permit an upgrade). All outcomes start on 'high' quality (those studies not an RCT start score 


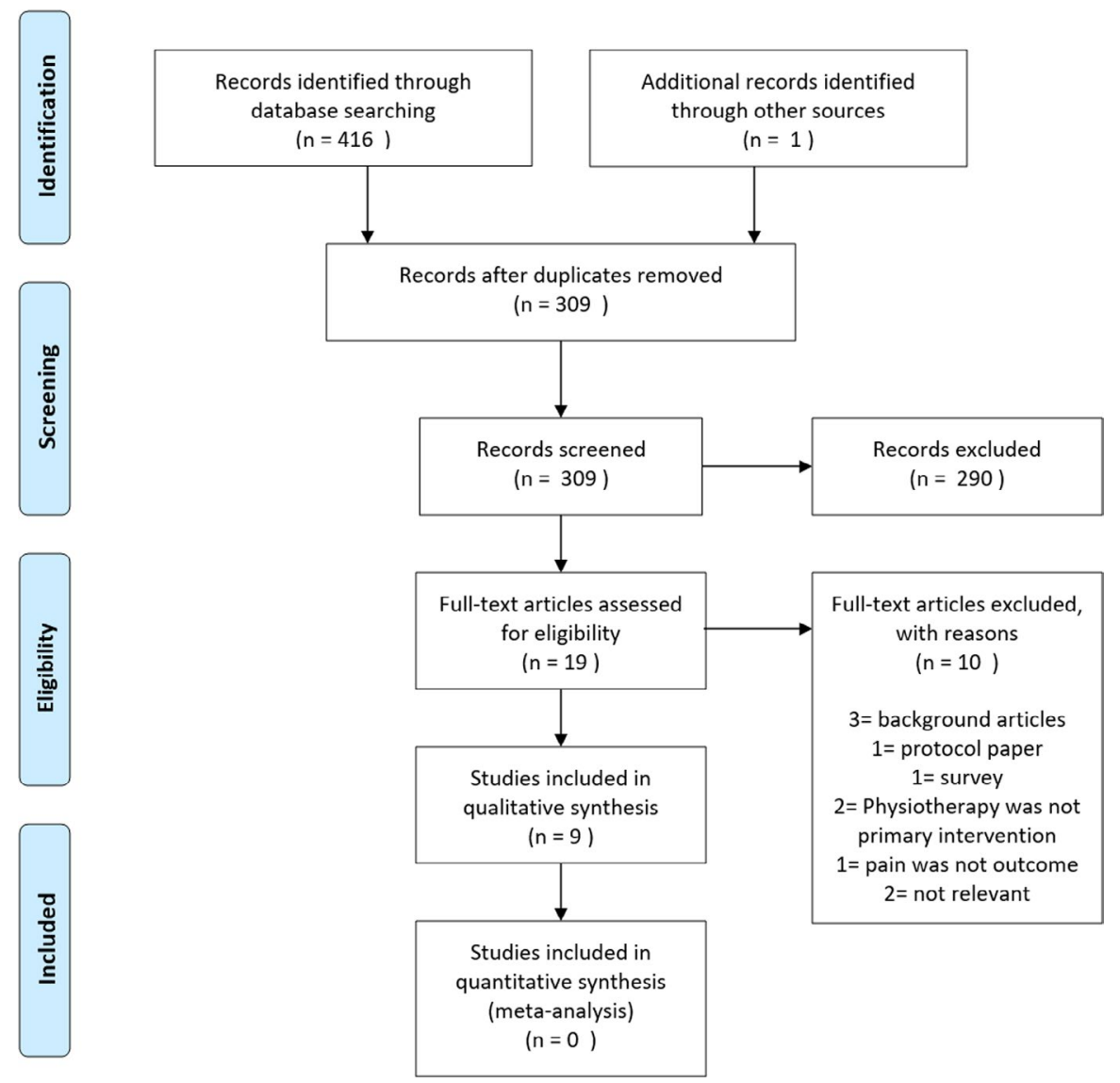

FIGURE 2 Flow chart of trial identification and selection for inclusion in review [Colour figure can be viewed at wileyonlinelibrary.com]

process on 'low'). They may then be downgraded one level per criteria if it is deemed to have a serious risk (-1) or very serious risk (-2). ${ }^{21}$

\subsection{0 | Additional analysis}

We were unable to undertake meta-analysis due to heterogeneity of the included studies.

\section{3 | RESULTS}

\section{1 | Study selection}

The search strategy identified 417 citations. Following removal of duplicates, 309 remained. Review of abstracts resulted in removal of 290 , with further 10 being removed after full text review (Figure 2).

\section{2 | Study characteristics}

Nine studies were identified (Table 1). The number of participants per study ranged from $9^{22}$ to $40 .{ }^{23}$ The number of participants across all studies was 235. Of these, 60 were children (aged 9-13) and 175 were adults (aged 26-58). Severity of haemophilia was not specified for 70 participants. Of the remaining 165, 93 were identified as having a diagnosis of severe haemophilia, 50 moderate, 17 mild and $5 \mathrm{mild} /$ moderate. One hundred and forty-nine participants were on prophylaxis and 46 were on-demand. Treatment regime was not stated for 40 people. Following GRADE assessment, all nine studies were rated as low/very low for quality of evidence.

\section{3 | Interventions}

Study intervention periods ranged from 3 to 15 weeks. Four trials had a RCT design. ${ }^{18,23-25}$

Four studies compared one physiotherapy intervention against another: passive joint mobilizations and exercise vs manual therapy and exercises in adults with haemophilic ankle arthropathy ${ }^{22}$; high intensity laser therapy (HILT) and exercise vs pulsed electromagnetic field and exercise in treatment of knee haemarthrosis in children ${ }^{26}$; home exercise programme and self-monitoring vs home exercise alone for haemophilic in adults with knee and ankle arthropathy ${ }^{27}$; and HILT and exercise vs placebo HILT and exercise in haemophilic arthropathy of the knee in children. ${ }^{28}$

Three studies in adults compared two physiotherapy intervention arms against a control group; manual therapy and exercise against patient education and exercise in haemophilic ankle 
arthropathy, ${ }^{24}$ with the same study design replicated for elbow arthropathy. ${ }^{18}$ A third study investigated hydrotherapy against land-based exercise with a control group in haemophilic knee arthropathy. ${ }^{23}$

Two studies in adults compared one physiotherapy intervention with a control group; patient education and home exercises verses control on elbow, knee and ankle haemophilic arthropathy ${ }^{25}$; and fascial therapy vs control on knee and ankle haemophilic arthropathy. ${ }^{29}$

One study performed the intervention 3 sessions per week for 3 weeks, ${ }^{29}$ with another not stating how many sessions were performed over 4 weeks. $^{23}$ Two studies performed the intervention for 2 sessions per week for 6 weeks, ${ }^{18,22}$ and one study encouraged participants to do exercises 10 times a day for 8 weeks. ${ }^{27}$ Another performed 2 sessions per week over 12 weeks ${ }^{24}$ with another doing 1 session every 2 weeks for 12 weeks. ${ }^{18}$ The participants in two studies received 3 sessions per week for 12 weeks $^{26}$ and another one session every 2 weeks for 15 weeks. ${ }^{25}$

\subsection{Risk of bias}

All studies had an overall risk of bias (see Figure 3). Assessment of risk of bias found agreement between study authors was moderate (Cohen's K 0.51).

\subsubsection{Sequence generation}

One study rated low risk as it described the use of a random number generation table for each participant. ${ }^{27}$ Six studies were rated as unclear risk as sequence generation methods were not described. One paper rated high risk as participants were chosen for inclusion based on geographical location. ${ }^{29}$

\subsubsection{Allocation concealment}

Two studies had a low risk with both describing opaque envelopes being distributed by someone unrelated to the study. ${ }^{18,25}$ Six studies were rated unclear due to lack of detail on methods of concealment. One study rated high risk as participants were selected based on geography. ${ }^{29}$

\subsection{3 | Blinding}

Blinding of the participants was not possible in any of the included studies, and none of personnel were blinded in any study. Five studies used blinded evaluators to assess outcomes ${ }^{18,22,24-26}$ and were rated low risk. Two studies rated unclear as they did not state if outcome assessment was blinded, ${ }^{23,28}$ and two rated high risk as outcome assessment was completed by the same individuals delivering the intervention. ${ }^{27,29}$

\subsection{4 | Incomplete outcome data}

Four studies rated as low risk of attrition bias because each stated that all participants completed the intervention. ${ }^{18,22,25,27}$ Five rated unclear as although they did not report dropouts, they also did not explicitly state that all had completed the intervention. ${ }^{18,24,26,28,29}$ One study was rated high risk as although the authors reported three dropouts, they did not specify from which group they came. ${ }^{23}$

\subsection{5 | Selective reporting}

Three studies were rated high risk of selective reporting bias. One study failed to report on changes to bleeding frequency even though this was an inclusion criteria for the study. ${ }^{26}$ Another describes an improvement in joint health with the Haemophilia Joint Health Score but include no data to support this ${ }^{28}$ and another does not report on all of the elbow joints included in their study. ${ }^{18}$ The six other studies had unclear risk of selective reporting bias.

No study was determined to have any source of other potential bias and therefore were rated as low.

\section{5 | Data synthesis}

Outcome measures for the nine trials are presented in Table 1. Although there were multiple outcomes measured across the trials, for the purposes of this review only those of pain intensity, quality of life and functional capability are included in this qualitative analysis, as per our protocol.

Data presented apply only to immediate postintervention assessments. All nine studies included an assessment for pain using the visual analogue scale (VAS). Two trials assessed health related quality of life (HR-QoL) using the A36 Haemophilia-QOL questionnaire. ${ }^{22,25}$ Physical function was assessed in three studies using the 6-minute walk test (6MWT), ${ }^{26}$ the 10 meter walk test (10MWT) and a modified functional reach test another. ${ }^{27}$ No other studies measured function or HR-QoL.

Where trials compared two physiotherapy interventions against a control, results from each intervention were analysed individually against the control (physiotherapy intervention vs no intervention), as well as against each other ( $\mathrm{A}$ vs $\mathrm{B}$ ).

\section{4 | PHYSIOTHERAPY VS NO INTERVENTION}

Five studies were included in this comparison (Figure 4). ${ }^{18,23-25,29}$ 
TABLE 1 Summary of included studies with GRADE assessment

\begin{tabular}{|c|c|c|c|}
\hline $\begin{array}{l}\text { Trial and } \\
\text { location }\end{array}$ & Methods & Participants & Intervention \\
\hline $\begin{array}{l}\text { Cuesta- } \\
\text { Barriuso } \\
2014^{22} \\
\text { (Spain) }\end{array}$ & $\begin{array}{l}\text { Quasi- } \\
\text { experimental } \\
\text { pre-post design }\end{array}$ & $\begin{array}{l}9 \text { Adults with haemophilia A or B } \\
\text { (mean age } 35.8 \text { ) and arthropathy in one or both } \\
\text { ankles on prophylaxis. } 3 \text { bilateral ankle arthropathy, } \\
5 \text { with right ankle arthropathy and } 1 \text { with severe } \\
\text { arthropathy left ankle. } \\
\text { Severe: } n=8(6=\text { SHA; } 2=\text { SHB) } \\
\text { Moderate: } n=1(\mathrm{HA}) \\
\text { Prophylaxis: } \mathrm{n}=9 \\
\text { (2-3/wk 'according to medical criteria') } \\
\text { Randomized into } 2 \text { groups: } \\
\text { A: Passive joint mobilizations }(n=4) \\
\text { B: Manual therapy }(n=5)\end{array}$ & $\begin{array}{l}6 \text { wk study period } \\
2 \mathrm{~h} \text { per week (both groups) } \\
\text { Both groups: infrared lamp start of session } \\
\text { Group A: passive joint mobilizations and muscle } \\
\text { exercises and proprioception } \\
\text { Group B: had manual therapy (joint distractions) and } \\
\text { muscle exercises and proprioception } \\
\text { Both groups cryotherapy to finish session }\end{array}$ \\
\hline
\end{tabular}




\section{Outcomes}

\section{Notes}

Not stated what baseline was for participants in each group (ie how many ankles (uni-or bilateral)-were affected in each individual)
GRADE assessment

Low

$\oplus \oplus \circ \circ$
VAS

HR QoL:

A36 Hemophilia QoL questionnaire

Ankle ROM:

Dorsi-, plantar-flexion, inversion, eversion

Proprioception: Romberg's test

\section{Calf Strength:}

Calf circumference

Ankle ROM:

Dorsi-, plantar-flexion, inversion, eversion Ankle pain:

VAS
Authors note that there were differences between the groups in terms of radiological deterioration, ROM and pain perception.

Potential variance between groups associated with severity of haemophilia. Control group had mostly moderate and on-demand treatment participants, whereas both intervention arms had mostly severe and on prophylaxis.

Participants handed records of home exercise compliance in every $2 \mathrm{wk}-$ but it was not stated if these were fully complete.
Very Low

$\oplus \circ 00$
Orthopaedic joint assessment: Gilbert Score

Pain intensity ankle, knee, elbow:

VAS

Quality of life:

A36 questionnaire

Illness behaviour questionnaire (IBQ)
This appears to be the same group of participants that have already been enrolled in all of the authors previous papers.

(? bias of results if participants have been exposed to previous interventions)
Low

$\oplus \oplus \circ \circ$ 
TABLE 1 Continued

\begin{tabular}{|c|c|c|c|}
\hline $\begin{array}{l}\text { Trial and } \\
\text { location }\end{array}$ & Methods & Participants & Intervention \\
\hline $\begin{array}{l}\text { Cuesta- } \\
\text { Barriuso } \\
2018^{18} \\
\text { (Spain) }\end{array}$ & $\begin{array}{l}\text { Single blind } \\
\text { randomized } \\
\text { study }\end{array}$ & $\begin{array}{l}27 \text { men with haemophilia (mean age } 34.48 \mathrm{yr} \text { ) and } \\
\text { elbow joint arthropathy } \\
\text { Overall: } \\
\text { Severe }(n=17) \\
\text { Mild }(n=10) \\
(\mathrm{HA}=22 ; \mathrm{HB}=5) \\
\text { Prophylaxis: } \mathrm{n}=15 \\
\text { On-Demand: } \mathrm{n}=12 \\
\text { Randomized to } 3 \text { groups- } \\
\text { Manual therapy: } \mathrm{n}=9(\mathrm{HA}=6 ; \mathrm{HB}=3) \\
\text { (Severe }=8, \text { Mild }=1) \\
\text { Prophylaxis }=7 \\
\text { On-Demand }=2 \\
\text { Education: } \mathrm{n}=9(\mathrm{HA}=8: \mathrm{HB}=1) \\
\text { (Severe }=6 ; \text { Mild }=3 \text { ) } \\
\text { Prophylaxis }=6 \\
\text { On-Demand }=3 \\
\text { Control: } n=9(\mathrm{HA}=8 ; \mathrm{HB}=1) \\
\text { (Severe }=3 ; \text { Mild }=6) \\
\text { Prophylaxis }=2 \\
\text { On-Demand }=7\end{array}$ & $\begin{array}{l}12 \text { wk study period } \\
\text { Follow-up assessment } 6 \text { mo after end of intervention. } \\
\text { Manual therapy group } \\
2 \times 60 \text { min per session per week: } \\
\text { Thermotherapy, elbow joint traction, elbow muscle } \\
\text { stretching, joint compression technique, passive } \\
\text { muscle stretching biceps/triceps, PNF of upper limb, } \\
\text { local cryotherapy. } \\
\text { Education group ( } 90 \text { min session every } 2 \text { wk, plus home } \\
\text { exercise programme } 20-30 \text { min daily): } \\
\text { Theory: anatomy/biomechanics of elbow, haematoma } \\
\text { management, joint bleed, synovitis, arthropathy, } \\
\text { proprioception, physical activity and sport. } \\
\text { Practical: Elbow ROM exercises, strengthening } \\
\text { exercises, exercise for mobility and pain management, } \\
\text { proprioception exercises } \\
\text { Control Group: usual routine }\end{array}$ \\
\hline $\begin{array}{l}\text { Donoso- } \\
\text { Ubeda } \\
2018^{29} \\
\text { (Spain) }\end{array}$ & $\begin{array}{l}\text { Non randomized, } \\
\text { controlled } \\
\text { before and after } \\
\text { trial }\end{array}$ & $\begin{array}{l}16 \text { men with haemophilia (mean age } 40.69) \text { and } \\
\text { haemophilic arthropathy of the knee and ankle. } \\
\text { Severe }(n=12) \\
\text { Moderate }(n=4) \\
\text { Prophylaxis: } n=16 \\
\text { Mean freq. every } 2.44 \text { d }( \pm 0.51) \\
\text { Mean dose FVIII/FIX }=2625 \pm 619.13 \text { units } \\
2 \text { groups: } \\
\text { Fascial therapy }(n=8) \\
\text { Control }(n=8)\end{array}$ & $\begin{array}{l}3 \text { wk study period } \\
3 \times 50-60 \text { min session per week. } \\
\text { Control: advised to maintain same level and conditions } \\
\text { of physical work and activity. } \\
\text { Intervention arm: Fascial therapy } \\
\text { No description given of patient position. } \\
\text { All manoeuvres done on both lower limbs except } \\
\text { thoracolumbar technique. } \\
\text { Superficial and deep fascial release techniques. }\end{array}$ \\
\hline
\end{tabular}




\section{Outcomes}

Safety of intervention

Elbow ROM:

Flexion/ extension

Arm circumference

Biceps strength

Pain intensity elbow:

VAS
Notes

Baseline imbalances between groups: more people with mild haemophilia in the control group (6) than the Manual therapy group (1).

Median VAS at baseline in education and control group was 0.

Results presented in median and IQR instead of mean and SD-emailed authors to request data in mean/SD which was made available
GRADE assessment

Low

$\oplus \oplus \circ \circ$

\section{Joint health:}

Haemophilia joint health score 2.1

Hamstring flexibility:

Finger to floor test

Lumbar mobility:

Schober test

Pain intensity right and left knee and ankle

in weight and non-weightbearing:

VAS

Pain intensity knee:

VAS

ROM knee

Flexion/ Extension

Swelling:

Tape measure around knee

Physical fitness:

6 min walk test (6MWT)

Laboratory investigations:

Erythrocyte sedimentation rate

Complete blood count including white

blood cells
No randomization

$\oplus \circ \circ \circ$
Poor description of intervention especially the physiotherapy programme. It was unclear when the laser was delivered in the session.

There are ethical concerns about why the investigators would expose both knees to PEMF as it did not state if both were affected (when the LASER group only treated one knee).

Unclear if rate of haemarthrosis continued to be once per week throughout intervention period.

No description of how acute, sub-acute haemarthrosis was assessed
Low

$\oplus \oplus \circ \circ$ 
TABLE 1 Continued

\begin{tabular}{|c|c|c|c|}
\hline $\begin{array}{l}\text { Trial and } \\
\text { location }\end{array}$ & Methods & Participants & Intervention \\
\hline $\begin{array}{l}\text { El-Shamy } \\
2016^{28} \\
\text { (Saudi } \\
\text { Arabia) }\end{array}$ & $\begin{array}{l}\text { Single-blinded, } \\
\text { placebo } \\
\text { controlled } \\
\text { randomized trial }\end{array}$ & $\begin{array}{l}30 \text { boys with Haemophilia A (aged 9-13) with } \\
\text { bilateral knee haemarthrosis. } \\
\text { Severity of haemophilia not stated. } \\
\text { Prophylaxis: } n=30 \\
\text { Regime not stated } \\
\text { Randomized into } 2 \text { groups: } \\
\text { Laser therapy ( } n=15 \text { ) } \\
\text { Sham Laser group }(n=15 \text { ) }\end{array}$ & $\begin{array}{l}3 \text { mo study period. } \\
3 \times 1 \text { h sessions per week. } \\
\text { Both groups: received a 'traditional' physiotherapy } \\
\text { programme that included hot packs, muscle } \\
\text { stretching and strengthening exercises, proprioceptive } \\
\text { training, balance and gait training. } \\
\text { Laser group: Laser from HIRO device. Positioning: knee } \\
\text { flexed to } 30 \text { degrees. } \\
\text { Initial phase performed with fast scanning for total of } \\
400 \text { J. Intermediate phase-applied hand piece to } \\
\text { total } 10 \text { points ( } 3 \text { in medial knee, } 2 \text { in lateral knee and } \\
3 \text { above patella, and } 2 \text { below patella) with a fluency of } \\
10 \text { mJ/cm }{ }^{2} \text { and a time of } 14 \text { s at each point for a total } \\
\text { of } 150 \text { J. Final phase-same as initial phase, except } \\
\text { that slow manual scanning was used with a total } \\
\text { energy of } 200 \text { J. } \\
\text { Sham Laser group: HILT machine switched on with a } \\
\text { visible light beam only-all parameters set up without } \\
\text { switching the start position of the machine }\end{array}$ \\
\hline $\begin{array}{l}\text { Goto } 2014^{27} \\
\text { (Japan) }\end{array}$ & $\begin{array}{l}\text { Prospective, } \\
\text { controlled, } \\
\text { randomized } \\
\text { non blind } \\
\text { comparative } \\
\text { stud }\end{array}$ & 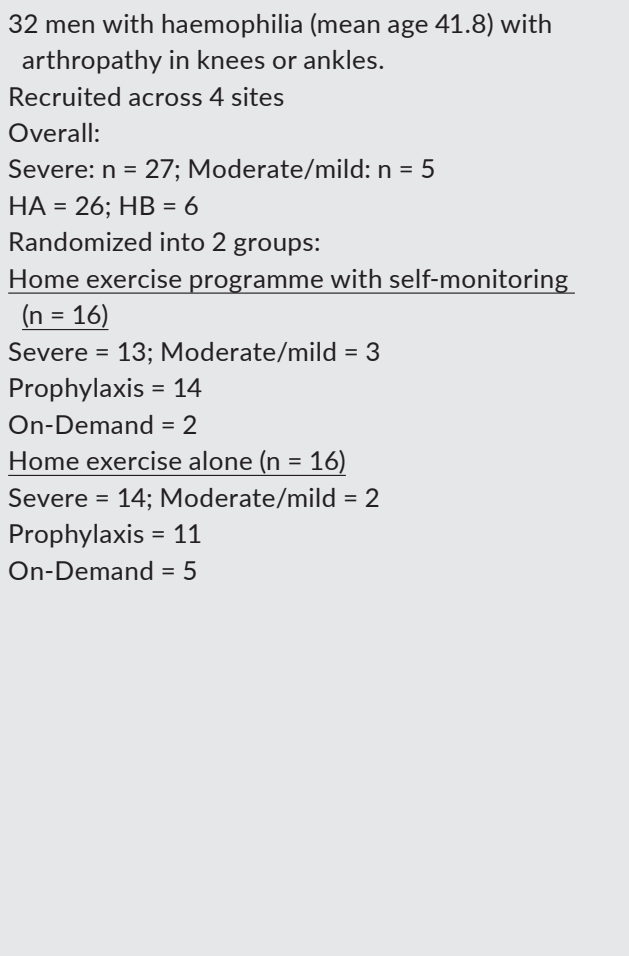 & $\begin{array}{l}8 \text { wk study period. } \\
\text { Both groups: given home exercise programme. } \\
\text { Only difference is the participants in the intervention } \\
\text { arm could review their progress on their monitors, } \\
\text { whereas the control arm group could not. } \\
\text { Home exercise programme-guidance about } \\
\text { strengthening knee extensors, static stretching for } \\
\text { knee flexors and standing balance training. Advice on } \\
\text { promotion of physical activity given by physio to } \\
\text { improve knee function. } \\
\text { Knee extension strength training, static stretches and } \\
\text { balance training } \\
\text { Advice on leading an active life and doing non-contact } \\
\text { sports were recommended for improving physical } \\
\text { activity. } \\
\text { ** physio recommended the exercise most appropriate } \\
\text { to the physical condition of each patient to be done } \\
10 \text { times per day } \\
\text { Self-monitoring: Participants were equipped with } \\
\text { display activity monitors and feedback system via } \\
\text { internet and mobile phone. When participants } \\
\text { accessed the server to data input-feedback results } \\
\text { appeared with time in form of graphs and tables. The } \\
\text { number of times performed exercises, physical } \\
\text { activity, bleeding frequency and injection of factor } \\
\text { were recorded }\end{array}$ \\
\hline $\begin{array}{l}\text { Mazloum } \\
2014^{23} \\
\text { (Iran) }\end{array}$ & $\begin{array}{l}\text { Quasi- } \\
\text { experimental } \\
\text { and prospective } \\
\text { trial with a } \\
\text { non-randomized } \\
\text { pretest-post- } \\
\text { test control } \\
\text { group }\end{array}$ & $\begin{array}{l}40 \text { people with haemophilia under } 50 \text { y old with } \\
\text { impaired knee joint ROM. } \\
\text { All severities-although exact numbers not stated. } \\
\text { HA or HB-not stated } \\
\text { Prophylaxis-not stated } \\
\text { Randomized to } 3 \text { groups: } \\
\text { Hydrotherapy ( } \mathrm{n}=14 \text { ) } \\
\text { Land-based exercise }(\mathrm{n}=13 \text { ) } \\
\text { Control Group ( } \mathrm{n}=13 \text { ) } \\
\text { Clotting factor taken before participation in activity } \\
\text { (dose not stated) } \\
\text { (Average age in each study group = } 33 \text { y) }\end{array}$ & $\begin{array}{l}4 \text { wk study period. } \\
\text { Hydrotherapy: Warm up ( } 5 \text { min)-co-ordinated and } \\
\text { rhythmic movement of lower limb in water. Exercises } \\
\text { ( } 30-45 \text { min) for hamstrings stretching, quadriceps } \\
\text { strengthening, from isometric to isotonic. Cool down } \\
\text { (5 min) gentle stretching } \\
\text { Land-based exercise: Warm up ( } 5 \text { min) simple } \\
\text { stretching exercises for muscles surrounding knee. } \\
\text { Main part (30-45) hamstrings stretching, quadriceps } \\
\text { strengthening, progressing from isometric to isotonic. } \\
\text { Cool down (5 min) of gentle stretching } \\
\text { Control: Not stated what was advised }\end{array}$ \\
\hline
\end{tabular}

Note: GRADE Key: $\oplus \oplus \oplus \oplus-$ High Quality-Confident that true effect lies close to that of estimate effect; $\oplus \oplus \oplus \circ-M o d e r a t e ~ Q u a l i t y-$ moderately

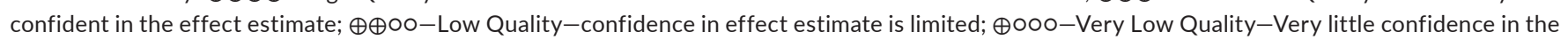
effect estimate. 


\section{Outcomes}

Pain intensity knee:

VAS

Functional capacity:

6MWT

Gait assessment:

Stride length, step length, velocity and cadence-using GAITRite system

\author{
Self-efficacy for exercise questionnaire: \\ Questionnaire not stated \\ Exercise adherence questionnaire: \\ Questionnaire type not stated \\ Quadriceps strength: \\ using hand held dynamometer \\ ROM: \\ Ankle-plantar-, dorsiflexion \\ Knee-flexion/ extension \\ Function: \\ Modified functional reach test \\ $10 \mathrm{~m}$ gait time \\ Pain intensity: \\ VAS \\ Physical Activity levels- \\ using activity monitor
}

Baseline imbalances of participants joint disease-ankle arthropathy was a much worse issue in the whole cohort even though the exercise plans carried out by participants was aimed at improving knee function.

Unclear who delivered the programme to intervention group across the 4 sites and how the programme was delivered
Very Low $\oplus \circ 00$
Pain intensity knee:

(VAS)

Knee ROM:

Flexion and extension
Number of sessions per week was not stated.

43 participants started study, but 3 dropped out (did not state from which group)
Very Low

$\oplus \circ \circ \circ$ 


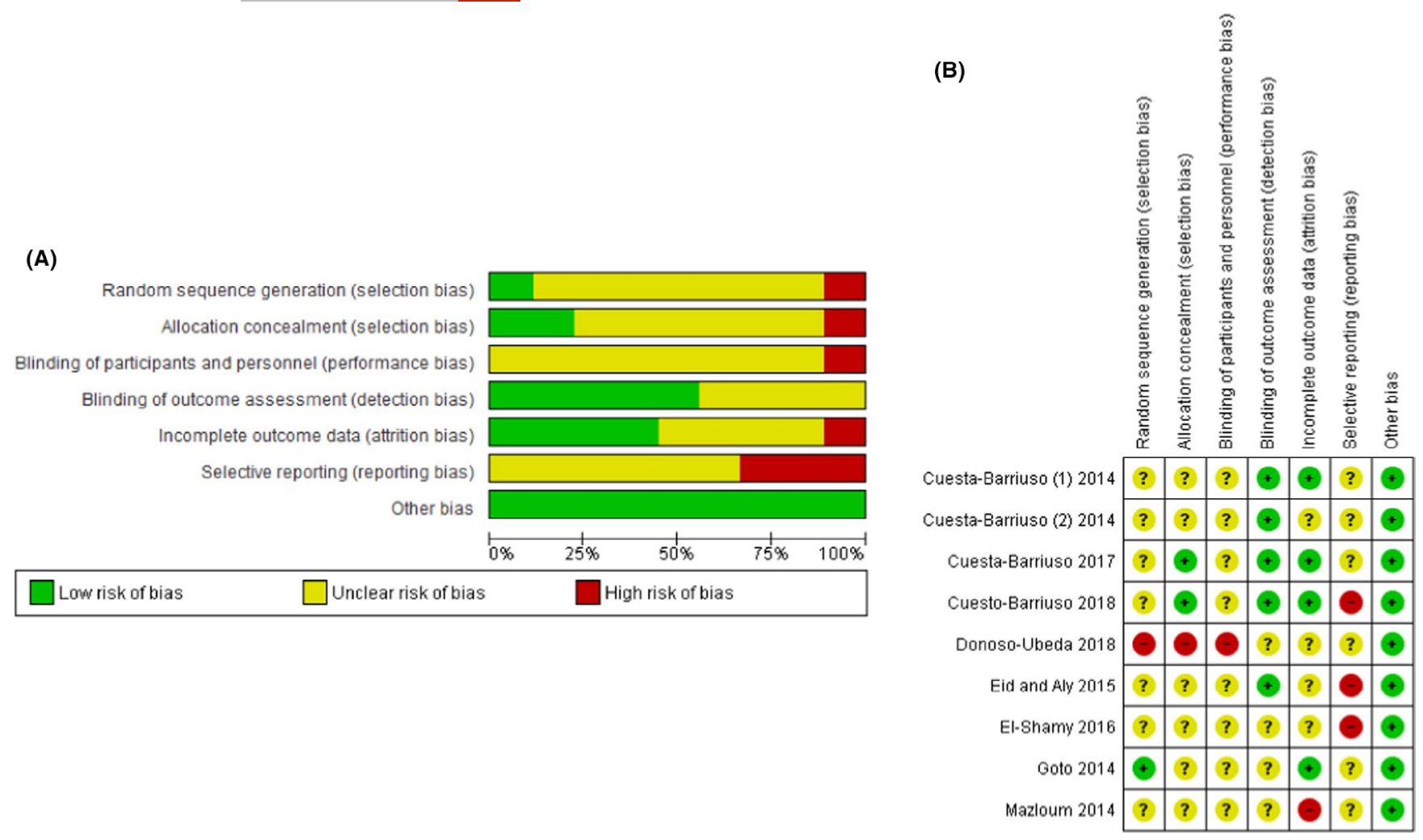

FIGURE 3 A, Risk of bias graph-author assessed risk of bias across all studies. (B) Risk of bias summary-author assessed risk of bias for each study [Colour figure can be viewed at wileyonlinelibrary.com]

\section{1 | Primary outcomes}

\subsection{1 | Pain}

All five trials included assessment of pain intensity using the visual analogue scale (VAS), with improvement in pain reported as a decrease in the VAS score. All were conducted on adults over 18 years of age, and apart from one study, ${ }^{29}$ all were RCT's.

\section{Elbow}

There was no clear benefit on pain intensity when using manual therapies and education on elbow pain, MD -0.30 VAS $(95 \% \mathrm{Cl}$ -0.92 to 0.32 ) or when using home exercises and education, MD -0.01 VAS ( $95 \% \mathrm{Cl}-0.34$ to 0.36 ).

\section{Knee}

There was no clear benefit on pain intensity when using home exercises and education, MD -0.75 VAS $(95 \% \mathrm{Cl}-2.13$ to 0.63 ) or fascial therapy, MD -0.87 VAS ( $95 \% \mathrm{Cl}-2.81$ to 1.07 ). Both hydrotherapy and land exercises were beneficial to knee pain intensity compared to no intervention. Hydrotherapy vs no intervention had a slightly stronger effect on pain intensity, MD -2.0 VAS $(95 \% \mathrm{Cl}-3.28$ to -0.72 ) compared to land-based exercise vs no intervention, MD -1.2 VAS ( $95 \% \mathrm{Cl}-2.54$ to 0.14$)$.
Ankle

There was no clear benefit on pain intensity with home exercises and education MD -0.55 VAS (95\% $\mathrm{Cl}-2.37$ to 1.27$)$, MD -0.3 VAS (95\% $\mathrm{Cl}-1.2$ to 0.6 ), or with manual therapy and exercise MD 0.06 VAS ( $95 \% \mathrm{Cl}-1.47$ to 1.6$)$. Fascial therapy showed a small positive effect of the intervention on right ankle pain intensity, MD -0.76 VAS ( $95 \% \mathrm{Cl}-1.39$ to -0.13$)$, but this was a study with high risk of bias.

\section{2 | Secondary outcomes}

\subsection{1 | Quality of life}

Only one study ${ }^{25}$ investigated the effects of patient education and home exercise programme $(n=10)$ compared to no intervention ( $n=10$ ) on patient reported quality of life. It is not clear if there is any beneficial effect of the intervention on quality of life, MD QoL 18.50 (95\% $\mathrm{Cl}-2.25$ to 39.25$)$.

\subsection{2 | Function}

None of the studies measured function as a outcome of intervention. 
(A) Hydrotherapy vs no intervention

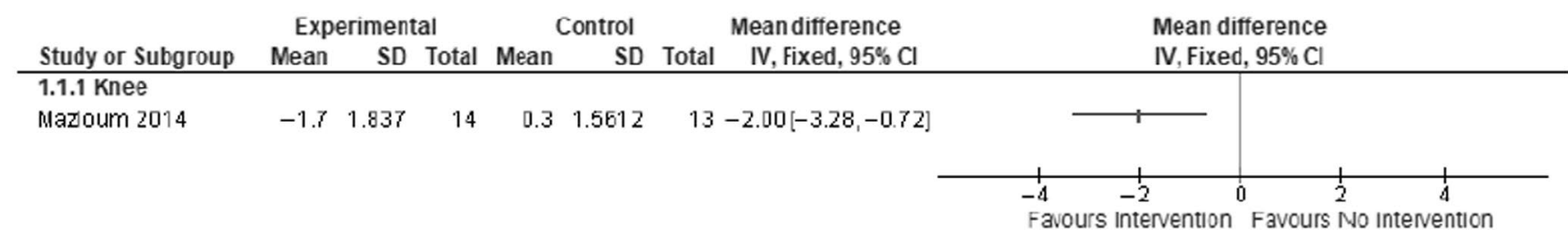

(B) Manual therapy and exercises vs no intervention

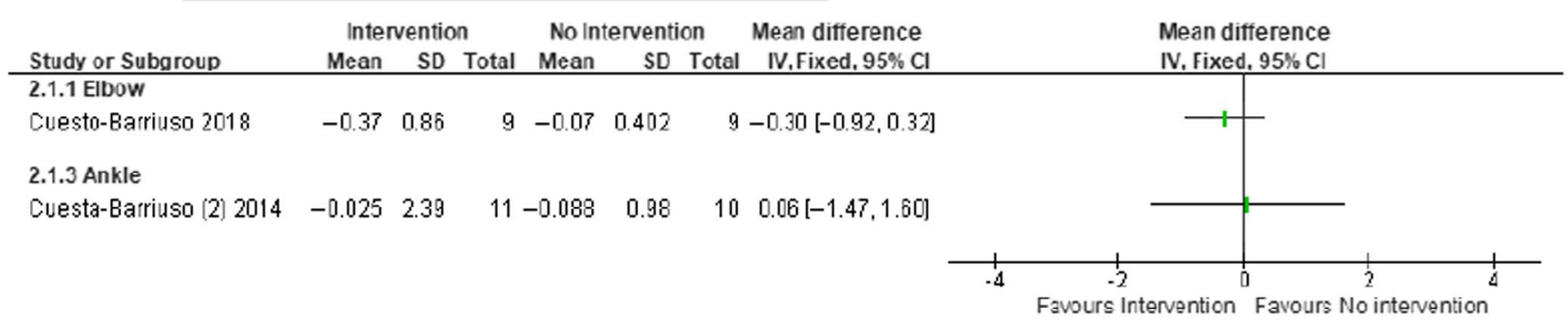

(C) Education and home exercise vs no intervention

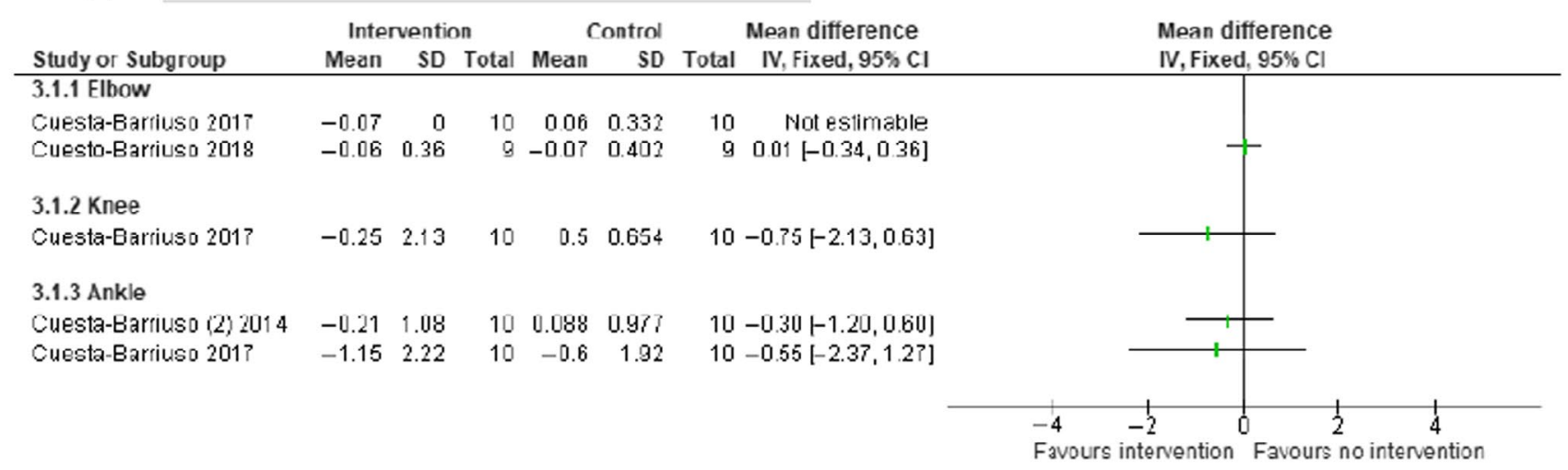

\section{(D) Land-based exercise vs no intervention}

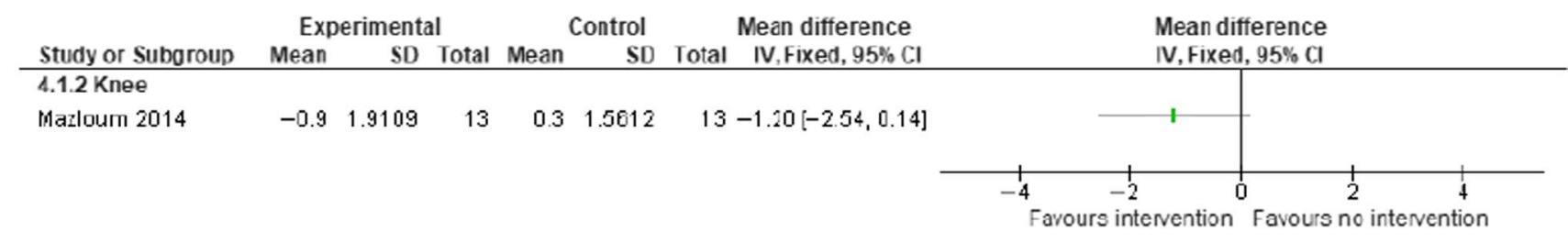

\section{(E) Fascial therapy vs no intervention}

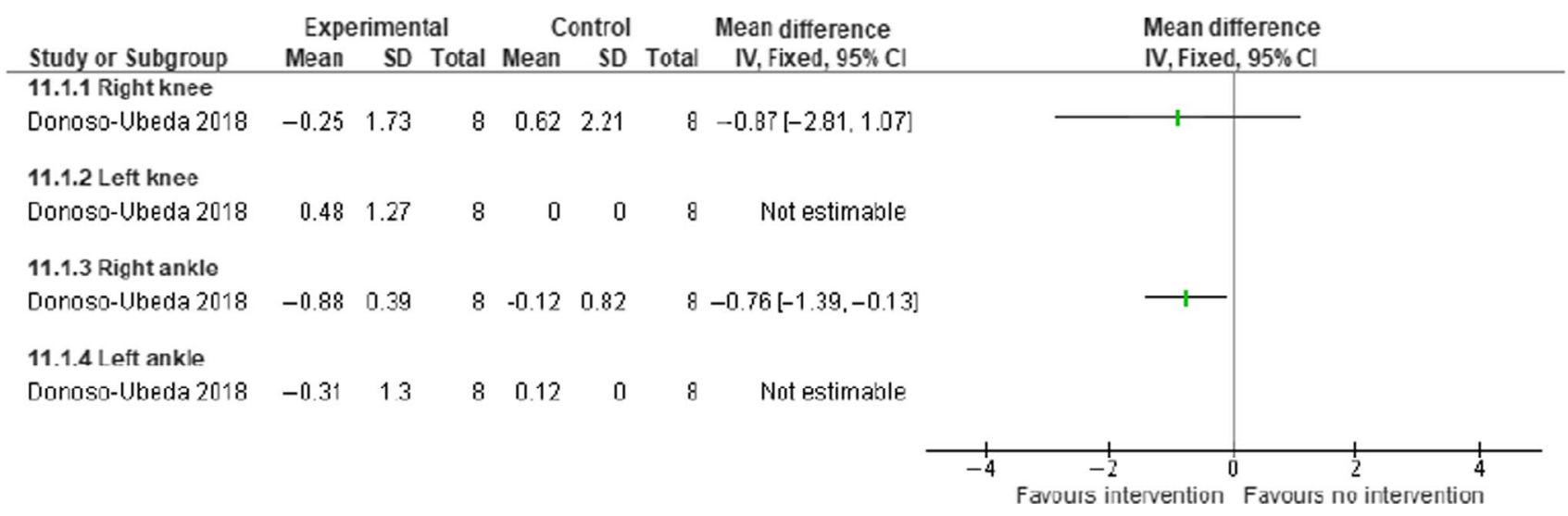

FIGURE 4 Comparison of physiotherapy intervention vs no intervention-Pain [Colour figure can be viewed at wileyonlinelibrary.com] 


\section{5 | PHYSIOTHERAPY INTERVENTION A VS PHYSIOTHERAPY INTERVENTION B}

Seven studies were included in this comparison (Figure 5). ${ }^{18,22-24,26-28}$

\section{1 | Primary outcomes}

\subsection{1 | Pain}

All seven trials included assessment of pain intensity using the visual analogue scale (VAS), with improvement in pain reported as a decrease in the VAS score. Five were conducted on adults over 18 years of age, and two on children between the ages of 9 and 13 .

\section{Elbow}

There was no clear demonstration of benefit for manual therapy and exercise over education and home exercises for elbow pain MD -0.31 VAS ( $95 \% \mathrm{Cl}-0.92$ to 0.3$)$.

\section{Knee}

Hydrotherapy has a more positive effect on knee pain than landbased exercise, MD -2.6 VAS (95\% $\mathrm{Cl}-4.02$ to -1.18$)$. LASER and exercise had a more positive effect on pain intensity than either sham laser left knee, MD -1.73 VAS $(95 \% \mathrm{Cl}-2.23$ to -1.23$)$ right knee, MD -1.61 VAS (95\% Cl -2.09 to -1.13$)$, or PEMF and exercise MD -1.07 VAS (95\% Cl -1.84 to -0.3$)$.

\section{Ankle}

There was no clear benefit on pain intensity when comparing mobilization and exercise with manual therapy and exercise MD 0.4 VAS $(95 \% \mathrm{Cl}-3.34$ to 4.14$)$, or manual therapy and exercise with home exercises and education MD 0.18 VAS $(95 \% \mathrm{Cl}-1.38$ to 1.75$)$.

\section{Pain (knee and ankle combined)}

It is not clear if there any beneficial effect on knee and ankle pain of a self-monitoring home exercise programme compared to an exercise programme alone, MD 0.62 VAS $(95 \% \mathrm{Cl}-0.37$ to 1.61$)$.

\section{2 | Secondary outcomes}

\subsection{1 | Quality of Life}

Only one study ${ }^{22}$ investigated the effect of a joint mobilization and exercise intervention ( $n=5$ ) vs a manual therapy and exercise intervention ( $n=4)$ on patient reported quality of life. The A-36 Haemophilia-QoL questionnaire was used. This is a 36 item questionnaire with a score range of 28-138 (higher score meaning better QoL). It is not clear if there is any beneficial effect on Quality of life from either intervention arm, MD -9.1 QoL $(95 \% \mathrm{Cl}$ -47.2 to 29$)$.

\subsection{2 | Function}

Three studies included a measure of function as an outcome measure of intervention.

It is not clear if there is any beneficial effect on function as measured by the 6MWT with LASER and sham LASER, MD 29.33 minutes $(95 \% \mathrm{Cl}-9.48$ to 68.14$)$, or LASER and exercise compared to PEMF and exercise, MD 14.47 minutes (95\% $\mathrm{Cl}-21.34$ to 50.38$)$.

It is not clear if there is any beneficial effect with self-monitoring and exercise vs exercise alone on modified reach test, MD $0.1 \mathrm{~cm}(95 \%$ $\mathrm{Cl}-7.64$ to 7.84 ) or on 6MWT, MD 0.4 seconds ( $95 \% \mathrm{Cl}-0.84$ to 1.64 ).

\section{6 | DISCUSSION}

This review presents the current evidence of trials utilizing a variety of physiotherapy approaches, with potential effect on pain intensity, quality of life and functional ability in $\mathrm{PWH}$. It demonstrates that currently, there is low/very low quality of unclear evidence of effectiveness of many physiotherapy interventions on these outcomes.

The studies included in this review highlight the wide range of interventions being studied. They included joint manual therapy, passive joint mobilizations, exercise interventions, patient education, high intensity laser therapy (HILT), pulsed electromagnetic field treatment, hydrotherapy and fascial release therapy.

Pain is an issue that many PWH state is one of their major concerns, ${ }^{30}$ yet no study included in this review defined pain as a specific inclusion criteria or ascertained if the presence of pain was of concern to participants. This may indicate assumptions made on the presence of pain based only on having haemophilia and/or arthropathy. Across many of the studies, the small differences in pre- and postintervention pain (VAS) highlight only a small change after intervention. It is unclear if this is due to a low pain VAS report preintervention (ie they had less/minimal pain upon starting the intervention) or a lack of effect of the intervention.

Only two studies included quality of life assessment, ${ }^{22,25}$ and three included an assessment of function. ${ }^{26-28}$ The minimal evaluation of psychological and social aspects of well-being alongside pain or basic joint function (such as ROM) makes no clear distinction of what the interventions mean to the individual taking part.

Physiotherapy trials can be considered a 'complex intervention'that is, an intervention containing several interacting components. Dimensions of complexity can include the following: the number of and interactions between components in the same experimental and control interventions, the number and difficulty of behaviours required by those delivering or receiving the intervention, number of groups targeted by the intervention, the number and variability of outcomes being measured and the degree of flexibility or tailoring of the intervention permitted. ${ }^{31}$ Haemophilia and its associated co-morbidities is a highly complex presentation, and as a result, any physiotherapy intervention would be, by-proxy, a complex intervention. Trials described here take no account of the potential complexity of the condition or the 
(A) Manual therapy and exercise vs Education and home exercise

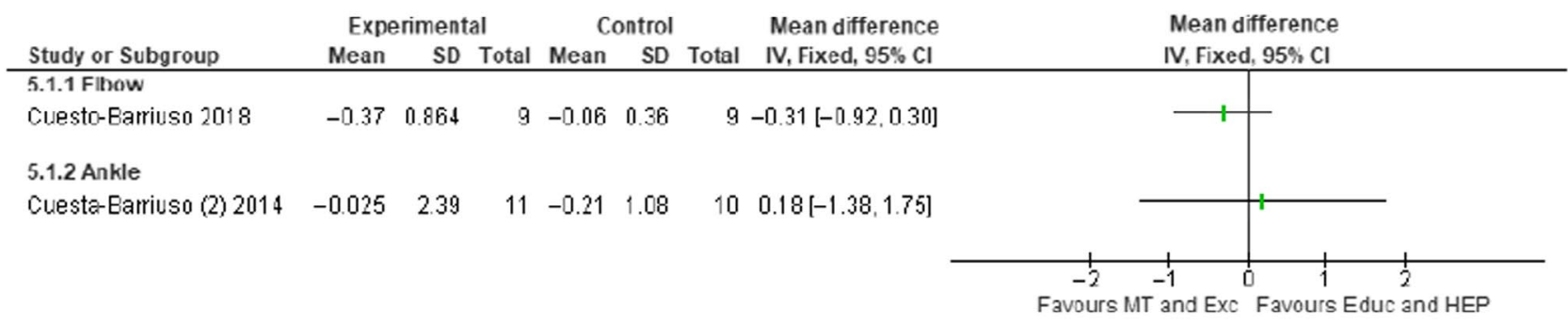

(B) Hydrotherapy vs land exercise

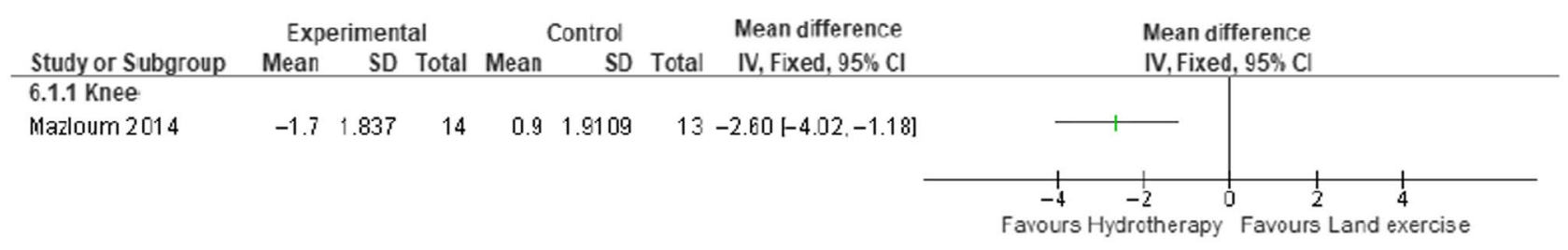

(C) Laser and exercises vs placebo laser and exercise

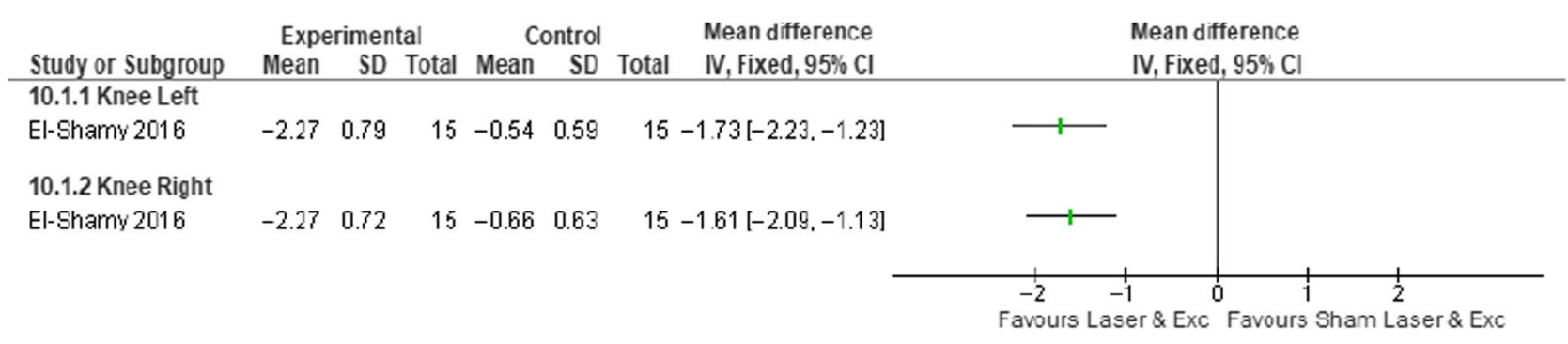

(D) Laser vs PEMF

\begin{tabular}{|c|c|c|c|c|c|c|c|c|c|}
\hline Study or Subgroup & \multicolumn{3}{|c|}{ Experimental } & \multicolumn{3}{|c|}{ Control } & $\begin{array}{l}\text { Mean difference } \\
\text { IV, Fixed, } 95 \% \mathrm{Cl}\end{array}$ & \multicolumn{2}{|c|}{$\begin{array}{l}\text { Mean difference } \\
\text { N, Fixed, } 95 \% \mathrm{Cl}\end{array}$} \\
\hline 7.1.1 Knee & & & & & & & & & \\
\hline Eid and Aly 2015 & -5.6 & 1.07 & 15 & -4.53 & 1.09 & 15 & $-1.07[-1.84,-0.30]$ & - & \\
\hline & & & & & & & & $\begin{array}{ll}-2 & -1 \\
\text { Favours Laser }\end{array}$ & $\begin{array}{ccc} & 1 & 1 \\
0 & 1 & 2 \\
& \text { Favours PEMF }\end{array}$ \\
\hline
\end{tabular}

(E) Manual therapy and exercise vs mobilizations and exercise

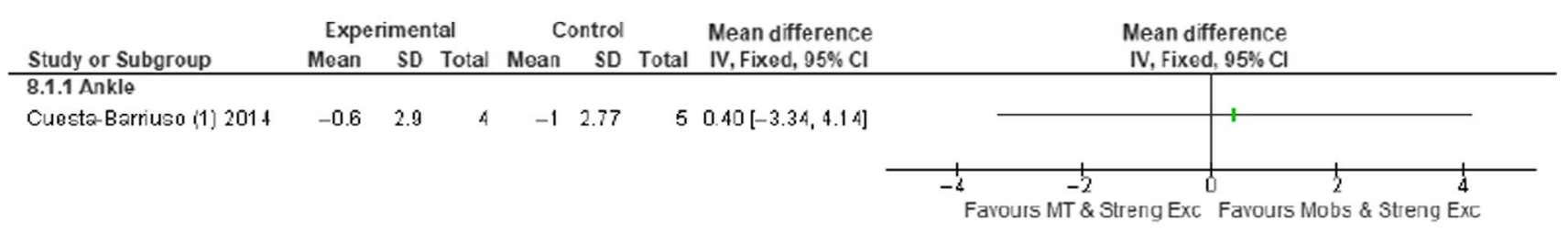

(F) Exercise and self-monitoring vs exercise alone

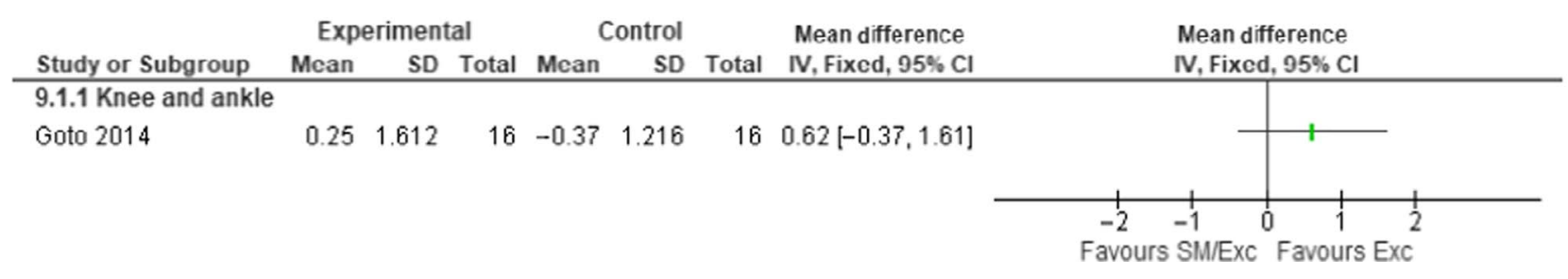

FIGURE 5 Comparison of physiotherapy intervention 'A' vs physiotherapy intervention 'B'-Pain [Colour figure can be viewed at wileyonlinelibrary.com] 
intervention, thereby making it difficult to evaluate them in their practical effectiveness or to identify how they may be exerting their effects.

Education showed little positive effect when used in conjunction with exercise or manual therapy. It is not clear from the studies how the teaching curriculum was developed. Including health education without consideration for potential behaviour change models of action limits evaluation of how any education provision may be having its effect. ${ }^{32}$

Previous systematic reviews share some similarities to this review. However, the quality of some of those reviews, as well as their results and recommendations, differs to those presented here. Although described as a systematic review, an evaluation of exercise and sport in the treatment of $\mathrm{PWH}^{33}$ lacked clear inclusion criteria as well as systematic analysis or comparison of data. In a narrative review of physical exercise, pain and musculoskeletal function in PWH Schäfer and colleagues ${ }^{34}$ described the data for intervention effectiveness and concluded that exercise promoted a reduction in pain, improved ROM and strength in $\mathrm{PWH}$. However, mean change from baseline together with confidence intervals was not reported or compared. They also reported low risk of bias in three studies that we assessed as having high risk, ${ }^{22,23,27}$ although this may be due to different assessment tools being used.

A recent Cochrane Review on Exercise for haemophilia ${ }^{35}$ was well conducted and included a broader range of outcomes in their analysis than this review. Similar to us, they noted major issues on study quality and stated that although exercise was likely safe, they urged caution with results as they stand.

Two further systematic reviews focussed on the treatment of chronic haemophilic ankle arthropathy ${ }^{36}$ and physiotherapy in the treatment of haemophilic arthropathy. ${ }^{37}$ The focus of the analysis in both was on the physiotherapy intervention itself rather than comparing the effects of those interventions on specific identified outcome measures. This makes it difficult to infer efficacy of any one specific intervention on measures such as pain and function. In contrast to our findings, the second review reported good study homogeneity, but it was not clear how this was evaluated.

Overall, the methodology and reporting quality of many of the included trials were poor. No study rated as high when being assessed for overall risk of bias. Many failed to provide details on randomization or participant allocation as well as appearing to omit some data in their overall results. High degree of trial heterogeneity was identified for both participants (severity of haemophilia, age range, location and number joints affected) as well as interventions (varied time frames for delivery, intervention components and outcome measures). Thus meta-analysis was not possible. Participant numbers were low for all included trials, and four of the trials were randomized pilot studies. ${ }^{18,22,24,29}$

Although overall safety from physiotherapy interventions was not included as an outcome for this review, it is acknowledged that physiotherapy interventions themselves may negatively influence pain, function and QoL. Safely participating in a rehabilitation programme is paramount from a haemostatic perspective as well as the perception of safety of the individual taking part. The limited detail on participant prophylaxis regimes limits further extrapolation of findings for others regarding intervention planning and safety, as does the heterogeneity of severity of disease in participants. None of the trials included only people with severe haemophilia-an important factor in considering the implications of potential effects of physiotherapy interventions, as severe haemophilia remains a diagnosis most likely to result in multi-joint arthropathy and pain. Further studies should seek to include all participant diagnostic and treatment information when reporting and publishing their results.

No studies appear to have involved PWH in the trial design, nor evaluated any qualitative measure of participation in such trials. As a rare disease, many $\mathrm{PWH}$ can be considered experts not just in their condition, but also in potentially identifying what matters to them in respect of rehabilitation interventions.

A strength of this review is the process of using two blinded reviewers throughout the process. Unlike many of the previous similar systematic reviews, we analysed the data to produce confidence intervals ( $\mathrm{Cl}$ 's) and mean difference (MD) figures, allowing a good visual representation of effectiveness. A limitation is that we were unable to proceed to complete a meta-analysis of the data from any of the included studies. This precludes any clear recommendations for the use of physiotherapy interventions in the management of pain in haemophilia.

Better design of trials is required and should include PWH in the process. Specific and defined inclusion criteria relating to haemophilia disease severity, as well as pain as a self-reported symptom, are needed to better assess efficacy of any interventions.

The current use of only VAS in measuring pain intensity requires further scrutiny. Pain as a multi-modal, personal, lived experience is poorly evaluated when measuring intensity alone. ${ }^{38}$ Further trials need to focus on how interventions may be designed to improve the physical, social, psychological and functional ramifications of a lifelived with pain.

\section{7 | CONCLUSION}

This systematic review highlights that there is currently an unclear demonstration of evidence for the use of physiotherapy interventions for pain management in people with haemophilia. LASER with exercise and hydrotherapy/land-based exercise appears to have some positive effect on knee pain in $\mathrm{PWH}$. However, caution must be taken with this recommendation due to poor quality reporting and high risk of bias in both trials. It is not possible to make recommendations on any other physiotherapy intervention in the management of pain in haemophilia. Improved trial design and methodology will allow this emerging body of research to be effectively collated and compared, to further develop effective interventions for pain in haemophilia.

\section{ACKNOWLEDGEMENTS}

We wish to express our thanks to librarian Anna El-Jouzi for her help and guidance in the development of the search strategy. 


\section{CONFLICT OF INTERESTS}

None of the authors have interests which may be perceived as posing a conflict or bias.

\section{AUTHOR CONTRIBUTION}

PML, DS and MH contributed to the study design. PML and DS contributed to data extraction and analysis for the review. All authors contributed to the development and review of the manuscript.

\section{DISCLAIMER}

This publication presents independent research funded by the NIHR. The views expressed are those of the authors and not necessarily of the NHS, the NIHR or the Department of Health and Social Care.

\section{ORCID}

Paul McLaughlin (iD https://orcid.org/0000-0002-5962-7647

Pratima Chowdary iD https://orcid.org/0000-0002-6690-8586

Kate Khair iD https://orcid.org/0000-0003-2001-5958

David Stephensen (iD https://orcid.org/0000-0002-6175-3343

\section{REFERENCES}

1. Witkop ML, Peerlinck K, Luxon BA. Medical co-morbidities of patients with haemophilia: pain, obesity and hepatitis C. Haemophilia. 2016;22:47-53.

2. Berntorp E, Shapiro AD. Modern haemophilia care. Lancet. 2012;379(9824):1447-1456.

3. Onwuzurike N, Warrier I, Lusher JM. Types of bleeding seen during the first 30 months of life in children with severe haemophilia $A$ and B. Haemophilia. 1996;2(3):137-140.

4. Philipp C. The aging patient with hemophilia: complications, comorbidities, and management issues. Hematology. 2010;2010(1):191-196.

5. Siboni SM, Mannucci PM, Gringeri A, et al. Health status and quality of life of elderly persons with severe hemophilia born before the advent of modern replacement therapy. J Thromb Haemost. 2009;7(5):780-786.

6. Wallny T, Hess L, Seuser A, Zander D, Brackmann HH, Kraft CN. Pain status of patients with severe haemophilic arthropathy. Haemophilia. 2001;7(5):453-458.

7. van Genderen FR, Fischer K, Heijnen L, et al. Pain and functional limitations in patients with severe haemophilia. Haemophilia. 2006;12(2):147-153.

8. Witkop M, Lambing A, Divine G, Kachalsky E, Rushlow D, Dinnen J. A national study of pain in the bleeding disorders community: A description of haemophilia pain. Haemophilia. 2012;18(3):e115 -e119.

9. Holstein K, Klamroth R, Richards M, Carvalho M, Pérez-garrido R, Gringeri A. Pain management in patients with haemophilia: a European survey. Haemophilia. 2012;18(5):743-752.

10. Kalnins W, Schelle G, Jost K, Eberl W, Tiede A. Pain therapy in haemophilia in Germany. Patient survey (BESTH study). Hamostaseologie. 2015;35(2):167-173.

11. Brodin E, Sunnerhagen KS, Baghaei F, Törnbom M. Persons with haemophilia in Sweden-experiences and strategies in everyday life. A single centre study. PLoS ONE. 2015;10(10):e0139690.

12. Beeton K, Neal D, Lee C. An exploration of health-related quality of life in adults with haemophilia - a qualitative perspective. Haemophilia. 2005;11(2):123-132.
13. Finney A, Healey E, Jordan JL, Ryan S, Dziedzic KS. Multidisciplinary approaches to managing osteoarthritis in multiple joint sites: a systematic review. BMC Musculoskelet Disord. 2016;17(1):266.

14. Baillet A, Zeboulon N, Gossec L, et al. Efficacy of cardiorespiratory aerobic exercise in rheumatoid arthritis: meta-analysis of randomized controlled trials. Arthritis Care Res (Hoboken). 2010;62(7):984-992.

15. Fransen M, McConnell S, Harmer AR, Van der Esch M, Simic M, Bennell KL. Exercise for osteoarthritis of the knee: a Cochrane systematic review. Br J Sports Med. 2015;49(24):1554-1557.

16. Liberati A, Altman DG, Tetzlaff J, et al. The PRISMA statement for reporting systematic reviews and meta-analyses of studies that evaluate health care interventions: explanation and elaboration. PLoS Medicine. 2009;6(7):e1000100.

17. Ouzzani M, Hammady H, Fedorowicz Z, Elmagarmid A. Rayyan-a web and mobile app for systematic reviews. Systematic Reviews. 2016;5(1):210.

18. Cuesta-Barriuso R, Gomez-Conesa A, Lopez-Pina JA. Manual and educational therapy in the treatment of hemophilic arthropathy of the elbow: a randomized pilot study. Orphanet J Rare Dis. 2018;13(1):151.

19. Centre TNC. Review Manager (RevMan). Copenhagen: The Cochrane Collaboration; 2014. Computer Programme.

20. Brożek JL, Akl EA, Alonso-Coello P, et al. Grading quality of evidence and strength of recommendations in clinical practice guidelines. Allergy. 2009;64(5):669-677.

21. Ryan R, Hill S. How to GRADE the quality of the evidence. Cochrane Consumers and Communications Group. Available at http://cccrg. cochrane.org/author-resources, Version 3.0, December 2016.

22. Cuesta-Barriuso R, Gómez-Conesa A, López-Pina J-A. Manual therapy in the treatment of ankle hemophilic arthropathy. A randomized pilot study. Physiother Theory Pract. 2014;30(8):534-539.

23. Mazloum V, Rahnama N, Khayambashi K. Effects of therapeutic exercise and hydrotherapy on pain severity and knee range of motion in patients with hemophilia: A randomized controlled trial. Int J Prev Med. 2014;5(1):83-88.

24. Cuesta-Barriuso R, Gómez-Conesa A, López-Pina JA. Effectiveness of two modalities of physiotherapy in the treatment of haemophilic arthropathy of the ankle: a randomized pilot study. Haemophilia. 2014;20(1):e71-e78.

25. Cuesta-Barriuso R, Torres-Ortuño A, Nieto-Munuera J, López-Pina JA. Effectiveness of an educational physiotherapy and therapeutic exercise program in adult patients with hemophilia: a randomized controlled trial. Arch Phys Med Rehabil. 2017;98(5):841-848.

26. Eid MA, Aly SM. LASER versus electromagnetic field in treatment of hemarthrosis in children with hemophilia. Lasers Med Sci. 2015;30(8):2179-2187.

27. Goto $M$, Takedani $H$, Haga $N$, et al. Self-monitoring has potential for home exercise programmes in patients with haemophilia. Haemophilia. 2014;20(2):e121-e127.

28. El-Shamy SM, Abdelaal AAM. Efficacy of pulsed high-intensity laser therapy on pain, functional capacity, and gait in children with haemophilic arthropathy. Disabil Rehabil. 2018;40(4):462-468.

29. Donoso-Úbeda E, Meroño-Gallut J, López-Pina JA, Cuesta-Barriuso R. Safety and effectiveness of fascial therapy in adult patients with hemophilic arthropathy. A pilot study. Physiotherapy Theory \& Practice. 2018;34(10):757-764.

30. Shapiro S, Stephensen D, Camp C, et al. The top 10 research priorities in bleeding disorders: a James Lind Alliance Priority Setting Partnership. Br J Haematol. 2019;186:e98-e100.

31. Craig P, Dieppe P, Macintyre S, Michie S, Nazareth I, Petticrew M. Developing and evaluating complex interventions: the new Medical Research Council guidance. BMJ. 2008;337:a1655.

32. Nutbeam D. Health literacy as a public health goal: a challenge for contemporary health education and communication 
strategies into the 21st century. Health Promotion International. 2000;15(3):259-267.

33. Gomis M, Querol F, Gallach JE, González LM, Aznar JA. Exercise and sport in the treatment of haemophilic patients: a systematic review. Haemophilia. 2009;15(1):43-54.

34. Schafer GS, Valderramas S, Gomes AR, et al. Physical exercise, pain and musculoskeletal function in patients with haemophilia: a systematic review. Haemophilia. 2016;22(3):e119-e129.

35. Strike K, Mulder K, Michael R. Exercise for haemophilia. Cochrane Database Syst Rev. 2016;12:CD011180.

36. Cuesta-Barriuso R, Gómez-Conesa A, López-Pina JA. Physiotherapy treatment in patients with hemophilia and chronic ankle arthropathy: a systematic review. Rehabil Res Pract. 2013;1-10.

37. Barriuso RC. Effectiveness of physiotherapy in the treatment of hemophilic arthropathy a systematic review. Annals of Hematology \& Oncology. 2017;4(9):1172.
38. de Williams AC, Davies HTO, Chadury Y. Simple pain rating scales hide complex idiosyncratic meanings. Pain. 2000;85(3):457-463.

How to cite this article: McLaughlin P, Hurley M, Chowdary P, Khair K, Stephensen D. Physiotherapy interventions for pain management in haemophilia: A systematic review. Haemophilia. 2020;26:667-684. https://doi.org/10.1111/ hae. 14030 